\title{
Joaquín Roca Rey: ergo sum
}

Samuel Montealegre

Mi corazón es tiesto regado de amargura; hay otros viejos pájaros que pastan dentro de él...

Melancolia, deja de secarme la vida, y desnuda tu labio de mujer...!

César Vallejo Avestruz

La idea de desaparecer del mundo angustia al hombre desde siempre; la religión le brinda un recurso con la inmortalidad, pero en otro lugar. Los artistas gozan del privilegio de pensar que seguirán en la tierra gracias a sus obras. Joaquín Roca Rey expiró en Roma, el 3 de septiembre de 2004 , en plena noche, pero su presencia ha sido y está garantizada aquí por su trabajo, realizado durante unas seis décadas. Las esculturas, los dibujos y los grabados nos dicen: ergo sum.

Durante muchos años establecimos con Joaquín una fraternidad solidaria. Las distintas orientaciones artísticas no impidieron una mutua comprensión del trabajo del otro, y quizás la afinidad en la educación sirvió para acercar nuestros caracteres tan distintos. Voy a detenerme en el hombre, porque pienso que para entender al artista es necesario conocer la lucha interior que lo acompañó y de la que brotó su arte, espejo de una personalidad compleja.

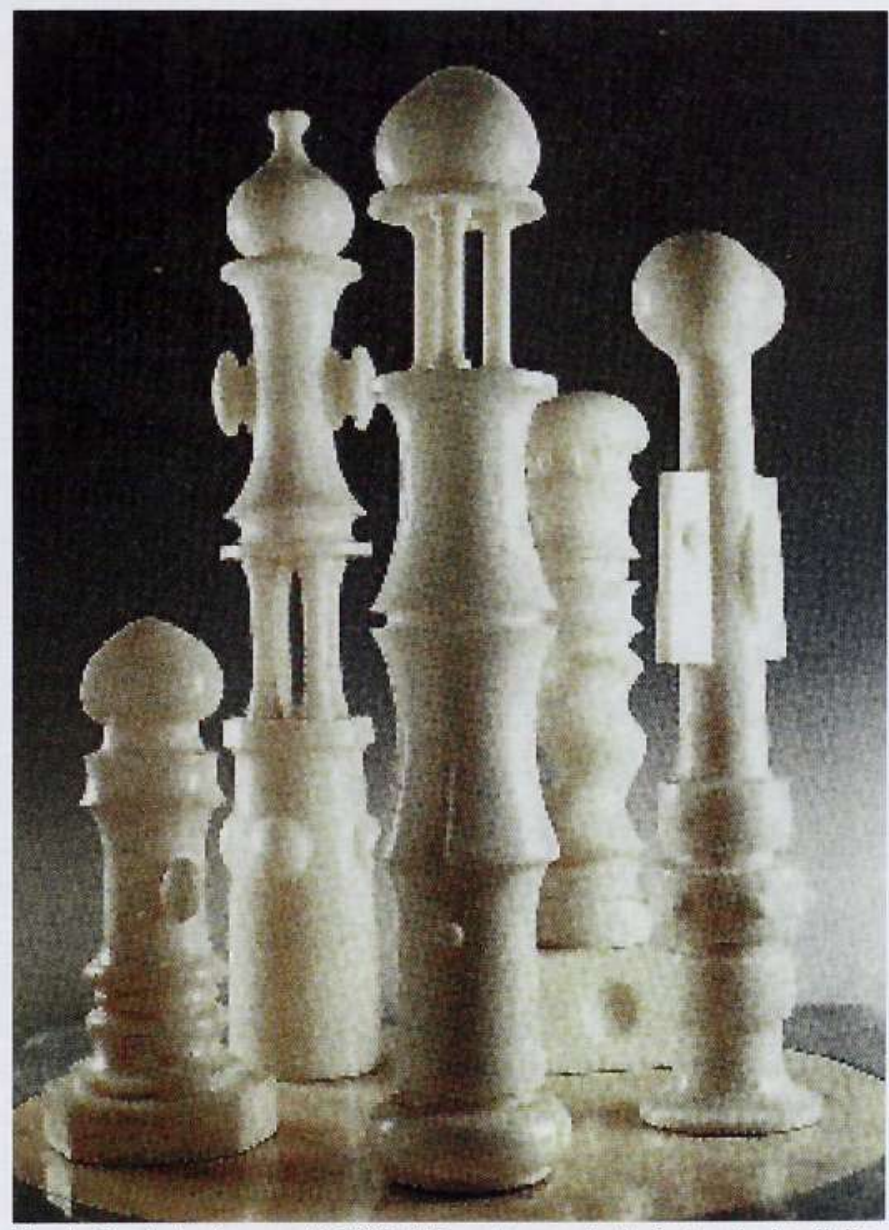

Fig. 1. Circolo degli ex-cacchi, 1975. Mármoles rosado de Portugal y bardiglio. $161 \times 80 \times 80 \mathrm{~cm}$. Roma, colección Sandra Roca Rey e hijos. Foto: Savio, Roma. 


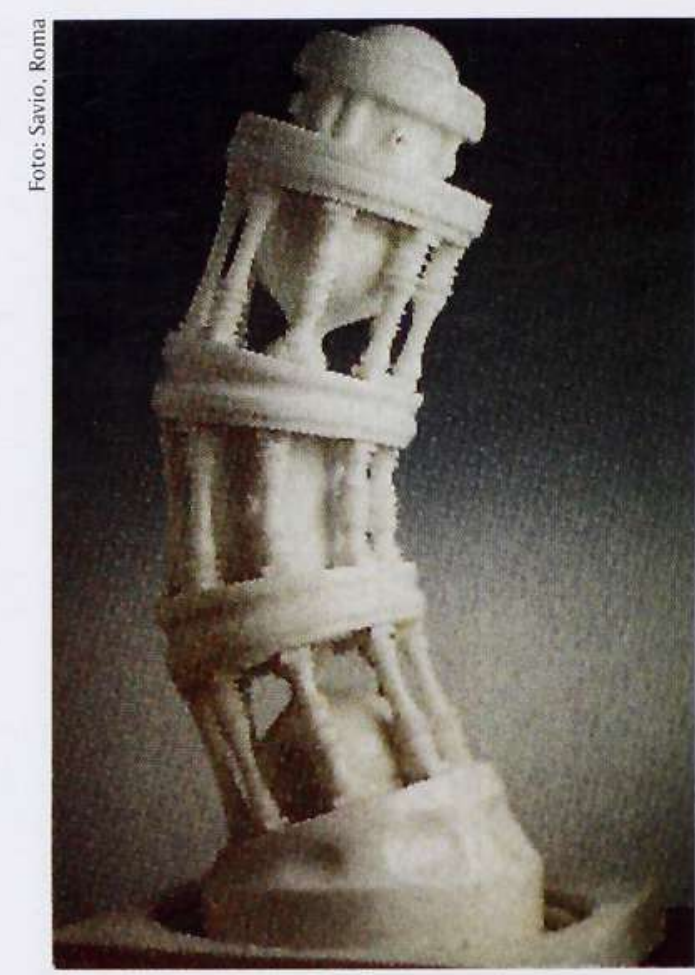

Fig.2. Gravidad de la torre, 1979-80. Mármol statuario. $81 \times 40.5 \times 40.5 \mathrm{~cm}$. Roma, colección Sandra Roca Rey e hijos

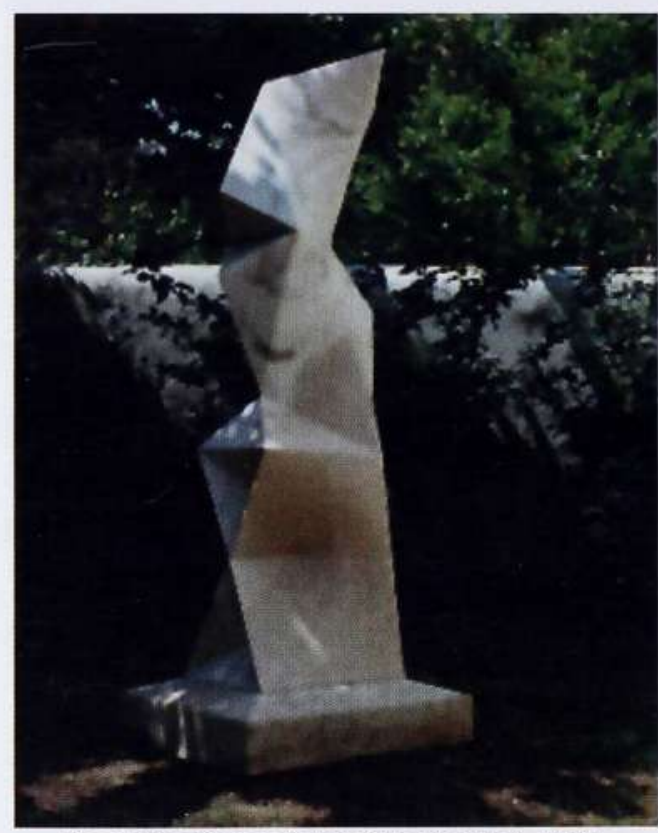

Fig. 3. Oración para Johann Sebastian Bach, 1991. Mármol rosado de Portugal. $219 \times 72.5 \times 85 \mathrm{~cm}$. Livorno, colección Giuseppe Mele y Sandrita Roca Rey.
Persona refinada, con un comportamiento intachable, pero, al mismo tiempo, atormentada, Roca Rey llega al mundo en una ciudad a orillas del Océano Pacífico, Lima, en un país con un pasado glorioso: el Perú. Crece en un ambiente y en una época en los que la forma social se considera indispensable y la ironía sirve para atenuar el ego, para hacerlo más liviano. Viaja mucho y por fin se radica en Roma, donde participa activamente en la vida cultural de la ciudad. A pesar de haber nacido y crecido en el litoral, estaba lleno de ese tormento del alma Ilamado melancolía, típico de la gente de los Andes. Todo el que haya estado en la cordillera andina sabe que allí se tiene la sensación de estar ineluctablemente solos con el propio destino, lo que predispone a una tristeza sutil contraria a la alegría de la gente del mar. Joaquín Roca Rey sentía el encanto del pasado; le gustaba rodearse de tejidos, piedras, cerámicas, oros... producidos por artistas y artesanos prehispánicos y por los del período colonial de América Latina. Su colección comprende también algunas piezas antiguas europeas y de otros continentes, y obras de artistas amigos.

Elegante, cortés, muy amable con todos, estaba lleno de gracia social, a pesar de la timidez, el profundo dolor existencial y el pesimismo alimentado por la obsesión de la muerte. Guardaba esa infelicidad para sí mismo, sin hacerla pesar a los demás; más bien hacía broma de ella. Sentía profundamente a Europa y la vivía con admiración.

El artista trasladaba su propia personalidad al arte, en el que se iban destilando sus pesadillas, comunicadas, sin embargo, refinadamente, como convenía a su manera de ser.

El fantasma de la muerte recorre la cultura de los pueblos precolombinos, así como la de los hispánicos injertada en ella. Roca Rey no trató nunca de sofocar ese atavismo; por el contrario, lo dejó aflorar, de modo que en su trabajo la muerte es un leitmotiv junto al sexo, conchabado con ella: los genitales masculinos y femeninos conviven con la muerte en un duelo sim-

biótico en el que ésta última siempre vencerá. En muchas obras, la vagina y el pene están representados de manera evidente; en otras, las líneas tomadas de ellos guían al ojo por caminos que permiten al cerebro la reconstrucción de imágenes ocultas: la línea recta, a veces dirigida hacia arriba, remite al pene en erección y en la base dos esferas u otra cosa imitan los testículos; ovoides, líneas entrantes y redondeces son tomadas de la vulva y de atributos femeninos como el seno. Se trata de trabajos con un sabor arquitectónico, para 
los cuales el artista se apoya completamente en la geometría, tanto en la estructura de la composición como en la imagen.

Cuando la imagen es explícita en la referencia figurativa, es superfluo descifrarla; pero en las obras arriba mencionadas, comenzadas en los años ochenta, la relación con los órganos sexuales, prevalentemente el masculino, es legible, es decir, consciente para quien conoce la obra anterior; de lo contrario, actúa sólo en el inconsciente.

En el segundo lustro de los años sesenta, realiza esculturas animadas que repetirá en el tiempo en distintos tamaños. Bronces, con una forma externa inspirada en los yelmos y los tabernáculos, que esconden la sorpresa: al abrir la "visera" o los postigos, la obra muestra en su interior órganos sexuales que con frecuencia se adelantan por medio de un mecanismo de pesos y contrapesos; el caballero exhibe su virilidad o piensa en las partes íntimas de la mujer,

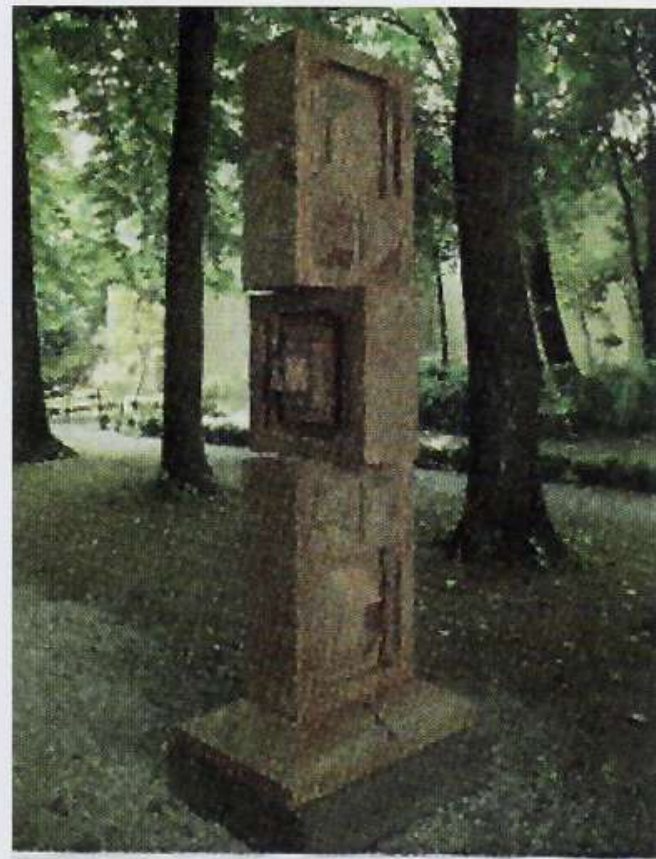

Fig. 4. Homenaje al poeta César Vallejo, 1988. Travertino rojo de Persia "Soraya". 220x90x70 cm. Viterbo, Cárcel.

y en lo sagrado se custodia el sexo. Sospecho que una variante de esta serie se ha inspirado en el albaricoque. Cuando el escultor oprimía el fruto para saborearlo, y éste se abría en dos descubriendo la semilla, lo observaba extasiado y elogiaba la sensualidad de lo que sucedía.

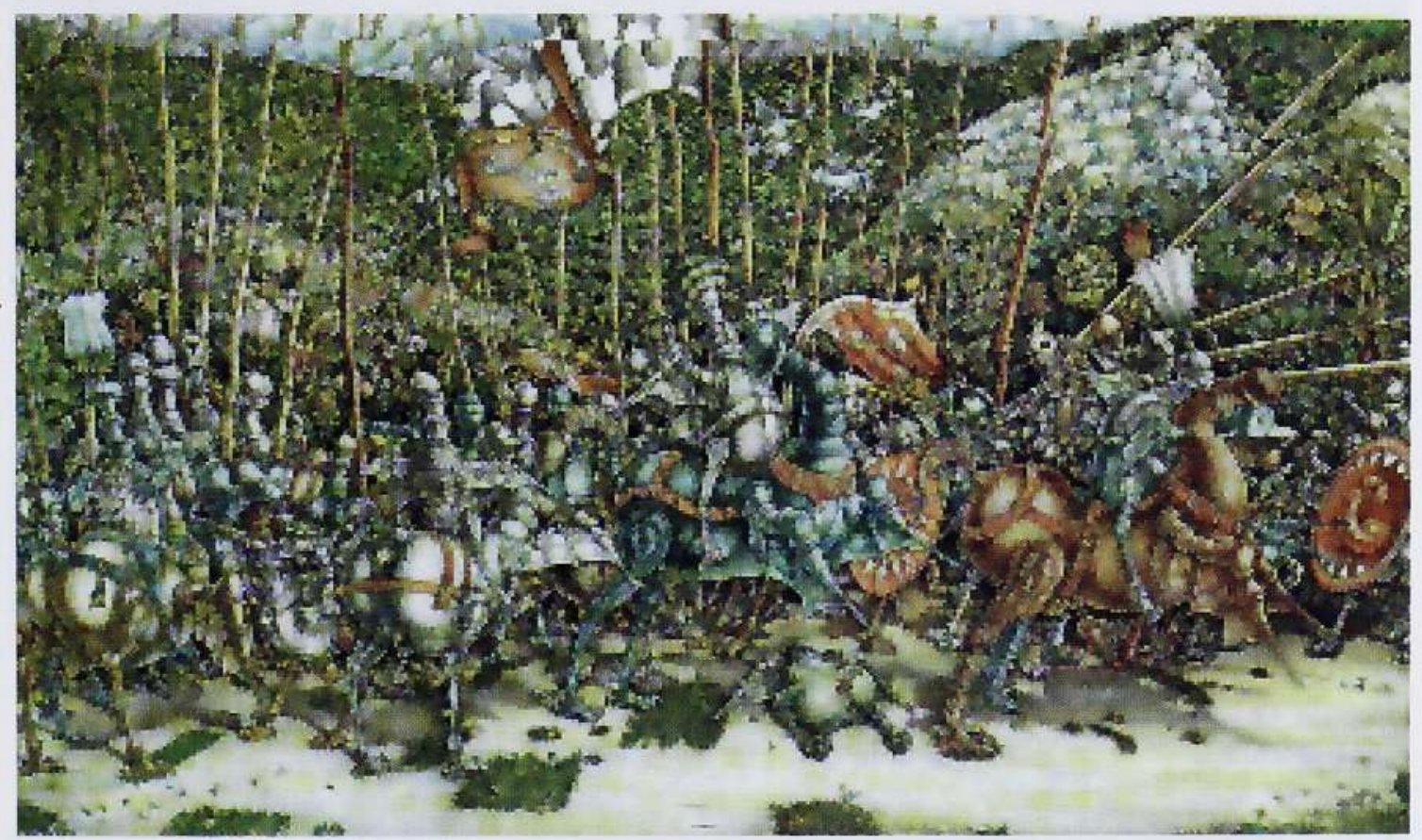

Fig. 5. Luccello è D-io, 1991. Acuarela sobre papel. $70 \times 100 \mathrm{~cm}$. Roma, colección Sandra Roca Rey e hijos.

Argumentos tan escabrosos esquivan cualquier complacencia pornográfica y, en cambio, se ven afligidos por un erotismo culpable; además, su elección está motivada por la necesidad sensorial, más que por una voluntad racional que habría convertido la obra en ilustración. 


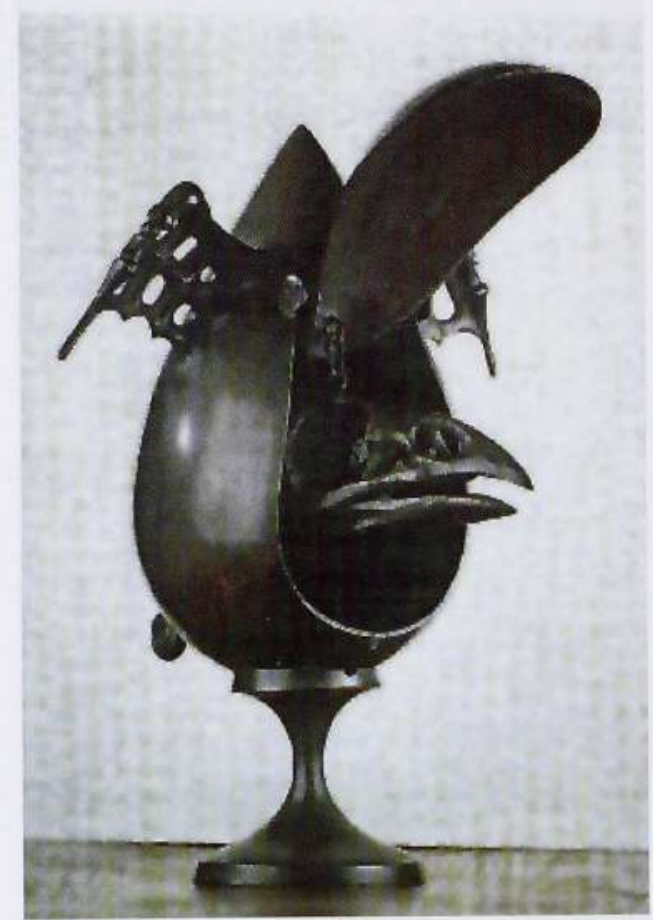

Fig. 6. Ave Caesar, 1980-82. Bronce, 50x41 x41 cm. Roma, colección Sandra Roca Rey e hijos.

Si es cierto que las imágenes de Roca Rey presentan sus tormentos, los terminados impecables transmiten la comunicación con gentileza. El material de las esculturas es pulido perfectamente, a la manera de un Donatello y del primer Miguel Ángel. Los dibujos dan prueba de un virtuosismo tomado de los grandes maestros grabadores. En tinta china, con pluma o con pincel, construye las imágenes modelándolas en rayitas, y con acuarela extiende el color. En la gráfica tiene predilección por el aguafuerte, pero utiliza también el aguatinta; se conoce una litografía, A Bolivar, y por un catálogo se sabe de otra, Requiem a Venecia. Algunos grabados están adornados con retoques grises de tinta china diluida.

La perfección en la ejecución se vuelve un imperativo ético para el artista, pues no quiere ofender con su psique angustiada: lo tenebroso se afina con el rigor técnico. Un pintor extraordinario y alterado como Edvard Munch, objetiva la infelicidad sin pudor también con la pincelada y el trazo. Roca Rey, en cambio, se propone una comunicación filtrada, utilizando medios tradicionales, una técnica probada y un lenguaje a-experimental bien dominado. De esto se desprende que, ante las obras del artista limeño-romano, nos sentimos ritualmente tranquilizados a pesar del malestar por lo que está representado; malestar atenuado también por la ironía que provoca una sonrisa y aleja el terror, mediando instancias divergentes: el drama y la cordialidad unidos por un humorismo fino, manifestado en los títulos, en los que juegan los dobles sentidos de las palabras descompuestas con tal objeto; el latín ha servido mucho para esto.

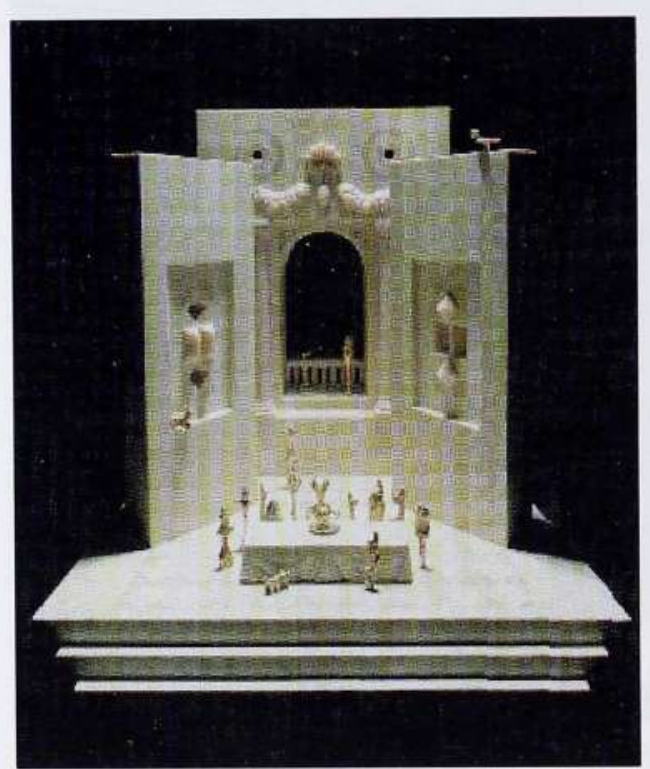

Fig. 7. Las bodas de don Juan (Homenaje a Mozart), 1990. Travertino, bronce y taraceas en mármol rosado de Portugal. $33.8 \times 37.8 \times 36 \mathrm{~cm}$. Roma, colección Sandra Roca Rey e hijos.
Maestros europeos, preferiblemente Paolo Uccello, son releidos por Roca Rey en trabajos en papel-obras en color, en blanco y negro y grabados-y, en términos amplios, constituyen operaciones interculturales y transtemporales. El artista respeta la estructura compositiva del original e inserta en ella sus fantasías erótico-macabras; en las hojas acuareladas, el cromatismo sufre transformaciones respecto al del original; los títulos remiten, con gracia, a las respectivas obras, cuando no es al nombre del autor mismo. Cuadros de Lucas Cranach el Viejo son reexaminados: La Crucifixión se transforma en Cranachfissione; otra obra recuerda el cuadro El Juicio de Paris y la titula Don Giovanni Cranachia, don Giovanni equivale a mujeriego. Reinterpreta también algún monumento: en mármol blanco la Torre de Pisa, reemplazando la diagonal de la pendencia por una combadura, alusión fisiológica.

¿Qué es lo que impulsa a Roca Rey hacia Paolo Uccello y por qué no elige artistas más 
afines a él en el mundo de lo fantástico, como Hieronymus Bosch? Es natural que su psique sienta la atracción por las batallas, la lucha cruenta que sirve de envoltura al eros. Pero existe un motivo más formal: los personajes que él introduce en las composiciones articuladas del pintor toscano resaltan porque se destacan, mientras que en las del artista flamenco se debilitarían, puesto que sus protagonistas ya están impregnados de lo irreal. Aunque parezca temerario, la operación realizada por Roca Rey en obras maestras de la historia del arte se acerca mucho a la de Marcel Duchamp, que dibuja bigote y perilla a una reproducción de la Gioconda. Ambos hacen burla. Duchamp desmitificando y Roca Rey desahogándose; el primero es racional; el segundo, emotivo. Picasso realizó reinterpretaciones de Las Meninas de Velázquez desestructurando la imagen; Roca Rey vacía los cuadros de sus protagonistas, respetando el escenario y la coreografía, para introducir otros intérpretes; de Las Meninas tomó el autorretrato del autor para hacer un busto con el rostro y el traje reconocible; lo demás, los miembros, son un esqueleto.

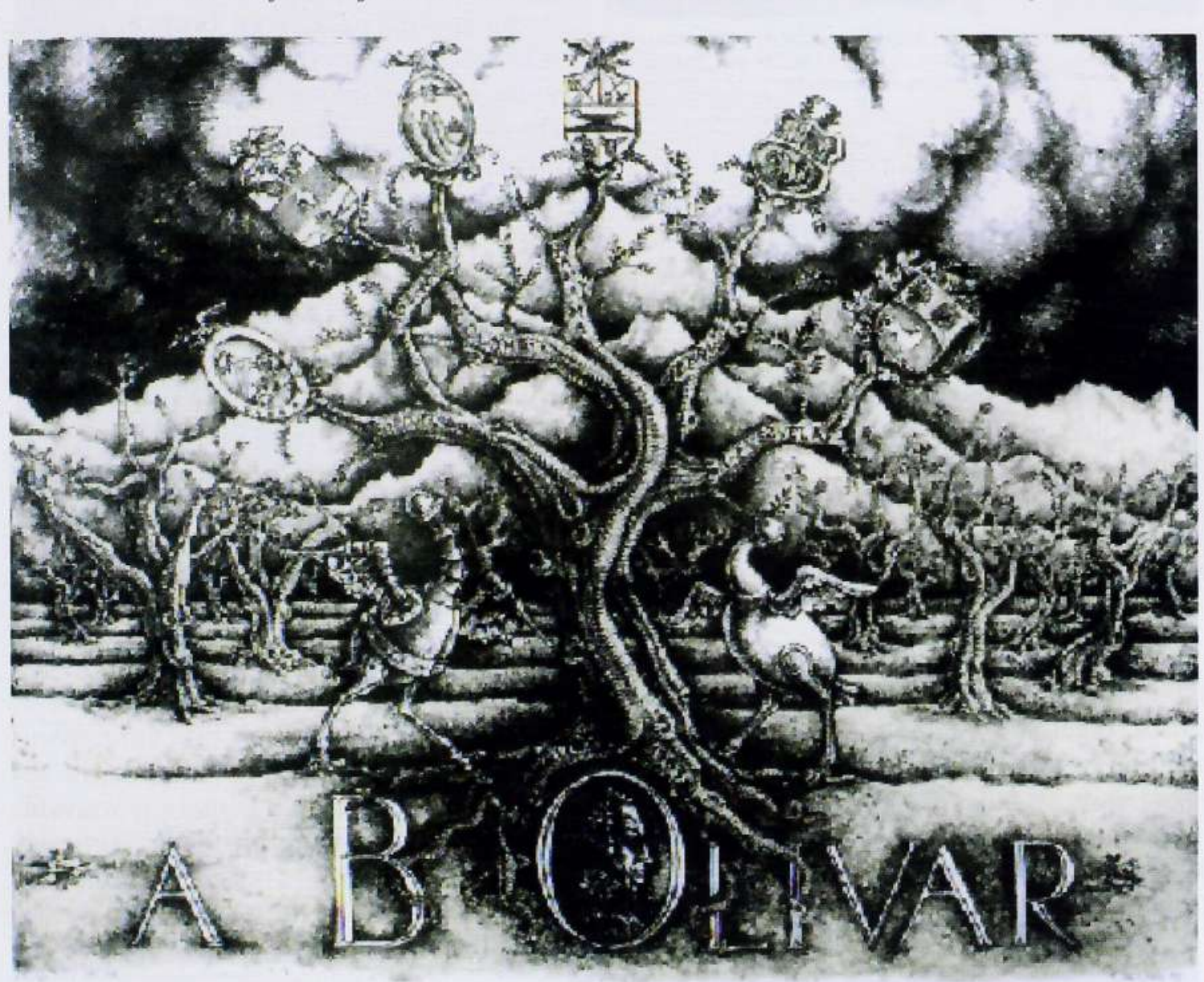

Fig. 9. Don Giovanni Cranachia, 1977. Aguafuerte 50 ejemplares. Imagen $327 \times 232 \mathrm{~mm}$.
Hoja 650x495 mm. Roma, colección Samuel Montealgre. Foto: Pirozzi, Roma.

Fig. 9. Don Giovanni Cranachia, 1977. Aguafuerte 50 ejemplares. Imagen $327 \times 232$ m
Hoja $650 \times 495$ mm. Roma, colección Samuel Montealgre. Foto: Pirozzi, Roma.

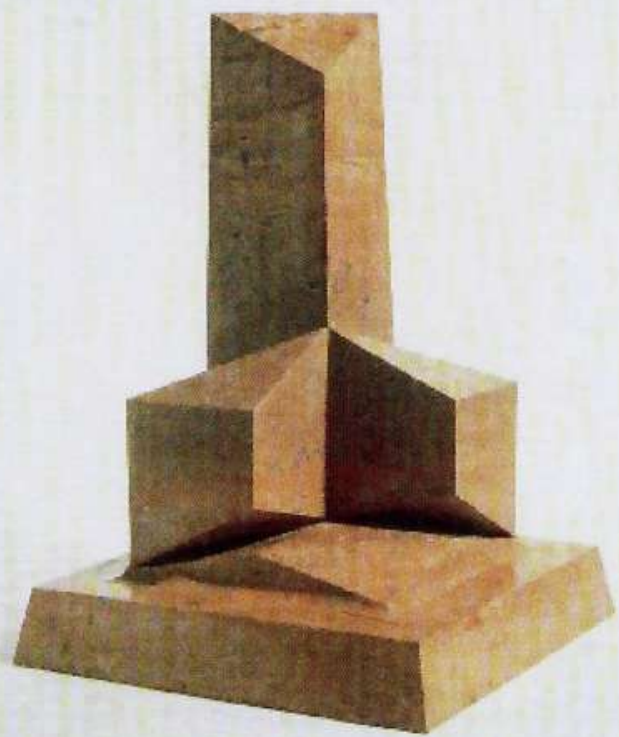

Fig. 8. Sursum corda, 1992. Travertino rojo de Persia "Soraya". 51x35.5x35.5 cm. Roma,

colección Sandra Roca Rey e hijos. 


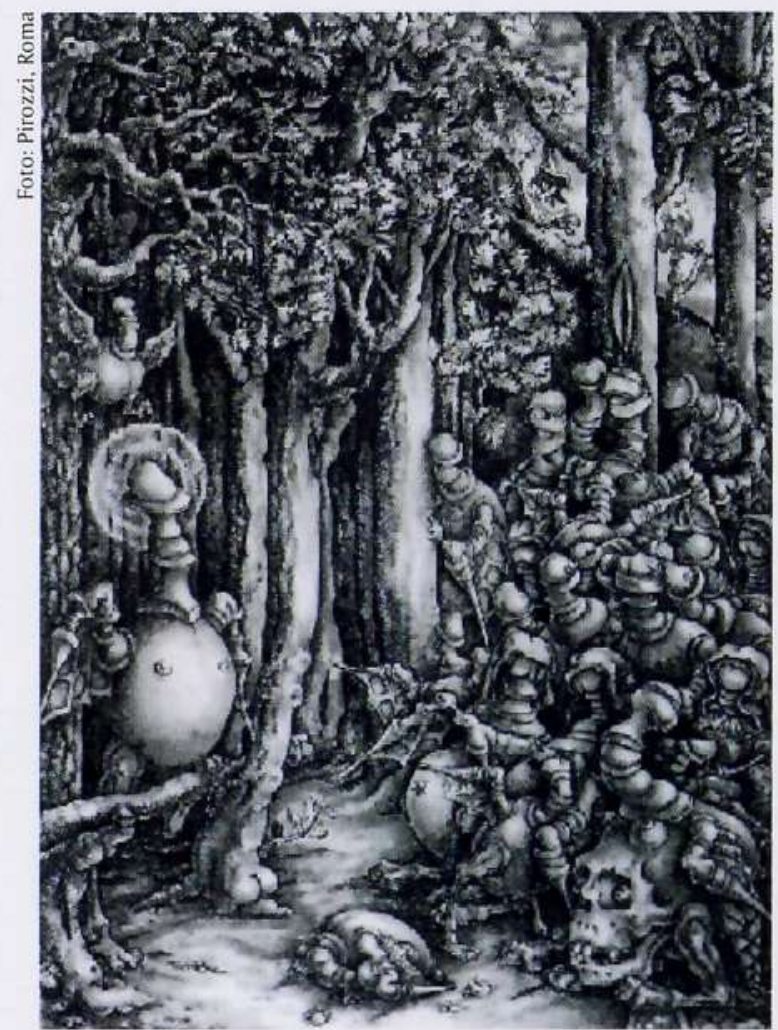

Fig. 10. A Bolivar, 1983. Litografía (editor Ana Mercedes Góez). Imagen 398x500 mm. Hoja $515 \times 700 \mathrm{~mm}$. Roma colección Samuel Montealgre.
Existe en el arte de Joaquín Roca Rey la intención de relacionar el propio mundo de procedencia, que él sigue amando, con Europa, que constituye su otro polo afectivo, en particular Italia, y especialmente Roma, de la que no podía prescindir.

Sentía un gran respeto por su compatriota, el poeta César Vallejo, y leía sus versos, lleno de emoción, identificándose con el pesimismo del vate. Experimentaba, justamente, vergüenza por la existencia miserable que él llevaba en París y se indignaba con el comportamiento de la clase directiva peruana de la época, sorda al talento. Le dedicó una escultura como prueba de admiración y con el objeto de reparar.

Joaquín era un melómano apasionado y se entusiasmaba con la música de Wolfgang Amadeus Mozart y de Johann Sebastian Bach. A Mozart le dedicó una escultura, un escenario en mármoles de colores con pequeños personajes en bronce; a Bach, una estela anicónica proyectada en triángulos que van disminuyendo hacia arriba. De este modo, interpretó magníficamen-

te su música: Mozart, la melodía, la lírica, la acción escénica, el juego; Bach, la estructura matemática, cuyas fugas están bien visualizadas en esta escultura de la que existen cuatro versiones en distintos tamaños y materiales (también Paul Klee sintió la atracción de Bach y tradujo su música en signos gráficos).

Roma es belleza sensual y racionalidad pragmática. Roca Rey vivió en esta ciudad desde 1963 y se vinculó a ella con cuarenta años de trabajo. Sü obra se coloca en el panorama romano, en antítesis con los parámetros formales y de contenido de la metrópolis y, por tanto, introduce en ella contrastes dignos de meditación. En la capital de Italia se exalta la belleza del cuerpo y se aleja el pensamiento de la muerte; Roca Rey se la coloca en primer plano. El romano imagina constantemente el sexo, y en esto habría una sintonía con el artista; pero en Roma se vive el sexo con una despreocupación pagana, mientras él lo presenta con un tormento religioso. Roma epicúrea fomenta la imagen de la felicidad y remueve la del sufrimiento; Roca Rey, estoico cristiano, pone de relieve el dolor y remueve la felicidad.

Traducción del italiano de María Cristina Montalvo de Dobrzensky. 